\title{
Complex respiratory and motor rehabilitation program in a patient with post-pulmonary tuberculosis conditions and multiple sequelae after SARS-CoV-2 infection: case report
}

\author{
DAIA Cristina ${ }^{1 \dagger}$, IONESCU Anca ${ }^{1 \dagger}$, IONESCU Elena Valentina ${ }^{2,3 \dagger}$, ILIESCU Mădălina Gabriela ${ }^{2,3 \dagger}$, \\ STANCIU Liliana Elena ${ }^{2,3 \dagger}$, CAMBREA Simona Claudia ${ }^{2,4 \dagger}$, ILIESCU Dan Marcel $^{2 \dagger}$, \\ ARGHIR Oana Cristina ${ }^{2,5 \dagger}$, POPESCU Marius-Nicolae ${ }^{1 \dagger}$, GEORGEANU Vlad ${ }^{1 \dagger}$, \\ VOINEA Felix ${ }^{2 \dagger}$, BAZ Radu ${ }^{2 \dagger}$, PAZARA Loredana ${ }^{2 \dagger}$, ONOSE Gelu ${ }^{1 \dagger}$
}

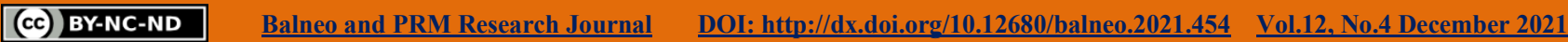
p: $301-305$

Editor: Constantin Munteanu, Romanian Association of Balneology, office@,bioclima.ro

Reviewers: Silisteanu Sinziana Calina and Gabriela Dogaru

*Corresponding authors: Cristina Daia, cristina.daia@umfed.ro ; Anca Ionescu, anca.ionescu@umfcd.ro

1 Department of Medical Rehabilitation, "Carol Davila" University of Medicine and Pharmacy, 041914, Bucharest, Romania;

2 Faculty of Medicine, «Ovidius» University of Constanta, 1 University Alley, Campus, Corp B, 900470, Constanta, Romania

3 Balneal Rehabilitation Sanatorium of Techirghiol, 900610,Techirghiol, Constanta County, Romania

4 Infectious Disease Clinical Hospital, 100 Ferdinand Blvd, 900709, Constanta, Romania

5 Pneumology Clinical Hospital,40 Sentinelei Str, 900002,Constanta, Romania

$\uparrow$ All Authors had equal contributions to this paper

\begin{abstract}
Introduction: A great variety of medical issues can occur after the COVID-19 infection including fatigue, muscle weakness, locomotor disability, self-care dysfunction, polyneuropathy, persistent dyspnea on exertion and a hypercoagulable state.

Materials and methods: This paper presents the case of a nonsmoker 49-year-old male with right lung lower lobe lobectomy for post tuberculosis bronchiectasis and diabetes mellitus, who developed multiple serious physicals, neurological, hematological and respiratory consequences, related to critical COVID-19 infection and prolonged hospitalization,

Results: A favorable evolution of the patient's respiratory sequels and motor impairment on both lower limbs was noticed after a complex individualized rehabilitation program started in the post COVID-19 Rehabilitation Department of Balneal and Rehabilitation Sanatorium, Techirghiol, Romania, consisting in better functional parameters and exercise tolerance, significant improvement in daily activities, remission of exertional dyspnea, social and family reintegration.

Conclusions: multidisciplinary approach and complex individualized programs of rehabilitation is required after a critical form of COVID in a patients known with tuberculosis, and other complex pathologies, in order to restore physical function and mobility and optimize respiratory parameters.
\end{abstract}

Keywords: COVID-19, Rehabilitation, Tuberculosis,

\section{INTRODUCTION}

A new strain of the Severe Acute Respiratory Syndrome Coronavirus 2 (SARS-CoV-2) was identified causing a very contagious infection, firstly described in Chinese patients, involving mostly human respiratory system ${ }^{1}$. Covid 19 is a challenging and polymorph pathology, ranges from asymptomatic to a severe respiratory form, implying extensive pneumonia and even death ${ }^{2}$. The list of the suggestive symptoms of COVID-19 includes fever, cough, breathing difficulty, chills, myalgia, headaches, sore throats, loss of taste (ageusia) and/or odor (anosmia), headache, conjunctivitis, and gastrointestinal problems $\mathrm{s}^{3,4}$. In a community-based study, involving self-reported symptoms to predict potential SARS-CoV-2 infection, via mobile application, the most prevalent symptoms were fever, persistent cough, fatigue, shortness of breath, diarrhea, delirium, missed meals, abdominal pain, chest pain and hoarse voice ${ }^{5}$. COVID-19 may also lead to longterm respiratory and cardiovascular consequences, physical and psychological dysfunctions, requiring early multidisciplinary rehabilitation ${ }^{6.7}$. The risk of death in
Romanian hospitalized COVID-19 patients is greater $^{8}$ than in tuberculosis ${ }^{9}$ or HIV patients ${ }^{10}$. Considering this data, our aim is to highlight the benefits of a complex rehabilitation program in a patient with post-pulmonary conditions and multiple sequelae after COVID-19.

\section{Case report}

\section{History data}

We report the case of a professional driver, nonsmoker male, aged 49 years old, with a suggestive medical history of recent COVID-19 infection known with diabetes mellitus, right lung lower lobe lobectomy for post tuberculosis bronchiectasis, in 1997. The patient was diagnosed and treated in Belgium, from December 2020 to February 2021, for a critical type of SARS-CoV-2 infection. The disease debuted with myalgia, fever, and fatigue while the patient was driving in Belgium. The COVID-19 infection was confirmed by positive RT-PCR testing and hospitalization was decided due to the presence of additional temporal-spatial disorientation. Despite the administration of antivirals, dexamethasone, 
invasive ventilation, and extracorporeal membrane oxygenation were required, after 10 days of hospitalization in the intensive care unit of Jan Palfijn Gent University Hospital, for an acute respiratory distress syndrome (ARDS). Extubation was considered after another two weeks of intensive medical care and the patient was then transferred to the Pulmonology Department for ventilator associated pneumonia caused by Pseudomonas Aeruginosa and Klebsiella pneumoniae, which treated and cured with a selected efficient combination of antibiotics (piperacillin - tazobactam, meropenem and ciprofloxacin). Following this long hospitalization period, a slow progressive favorable evolution was noticed, but it was grafted with multiple complications, consisting in difficulties in speech, swallowing and dysphagia, after prolonged oro-tracheal intubation, requiring special speech therapy exercises and feeding by nasogastric tube. Type 2 diabetes mellitus was revealed by persistent hyperglycemia and elevated values of glycated hemoglobin (8.6) requiring therapy by rapid acting insulin in combination with methformin. At discharge, after two months, the treatment recommended were: pregabalin $150 \mathrm{mg}$ twice a day, metformin $850 \mathrm{mg}$ three times daily, and $0.4 \mathrm{mg}$ of tamsulosin and $60 \mathrm{mg}$ of gliclazide once a day.

\section{Patient's evaluation}

In February of 2021, the patient was admitted to the Balneal and Rehabilitation Sanatorium of Techirghiol (BRST), Romania. At admission, he complained of mechanical pain in the right knee, hands and fists, hypoesthesia and paresthesia of the distal region on both lower limbs, muscle weakness with marked muscle atrophy and motor impairment on both lower limbs, bilateral motor dysfunction on the dorsiflexion of the foot (mostly on the left side), persistent exertional dyspnea, marked physical asthenia, fatigue and general deconditioning due to the prolonged hospitalization.

Clinical examination revealed: motor deficit in both legs, mostly on the left leg; left muscular force were dorsiflexion $2+$, inversion $3+$, plantar flexion 4+; right muscular force: dorsiflexion 3+, inversion 4, plantar flexion 5, dorsal hypoesthesia of the left leg. The pain in the right knee was associated with slight antero-posterior instability, generalized muscle hypotrophy in the lower limbs.

The 6-minute walking test (6MWT) was performed, covering a distance of 290 meters, and revealed exertional dyspnea and mild desaturation (Table 1). Performance of daily activities was evaluated on a scale with 10 points, from 0 to 10 , 0 meaning "no problems" and 10 meaning "cannot be performed". The ability of climbing stairs 5, running 7 and lifting weights 6 .

TABLE 1. 6 minutes walking Test at admission in Balneal and Rehabilitation Sanatorium of Techirghiol

\begin{tabular}{|c|c|}
\hline Before walking & $\begin{array}{c}\text { After walking for } 290 \\
\text { meters }\end{array}$ \\
\hline $\mathrm{TA}=120 / 80 \mathrm{mmHg}$ & $\mathrm{TA}=140 / 90 \mathrm{mmHg}$ \\
\hline $\mathrm{AV}=96 \mathrm{rpm}$ & $\mathrm{AV}=106 \mathrm{rpm}$ \\
\hline $\mathrm{SpO} 2=99 \%$ & $\mathrm{SpO} 2=94 \%$ \\
\hline WITHOUT dyspnea & Dyspnea \\
\hline \multicolumn{2}{|c|}{ TOTAL DISTANCE COVERED $=290$ meters } \\
\hline
\end{tabular}

Paraclinical blood exam emphasized increased d-dimers up to $5380 \mathrm{ng} / \mathrm{ml} 24$ times higher compared to normal value, and anticoagulation with apixabam pills of $2.5 \mathrm{mg}$ twice a day was initiated after cardiologist evaluation.

Pelvis radiography showed femoral impingement by elevation of the bilateral cervical-cephalic lateral contour, especially on the left side.

Electromyographic investigation: mixed symmetrical, predominantly motor polyneuropathy with mostly distal involvement.

Ultrasound examination of the left common peroneal nerve revealed peripheral nerve imaging of injury, with clear configuration and detachment without extensive pressure.

Chest computed tomography revealed: subpleural area of fibrosis and traction bronchiectasis in the left lower lung lobe, right lower lung lobe lobectomy and mediastinum shift to the right hemithorax.

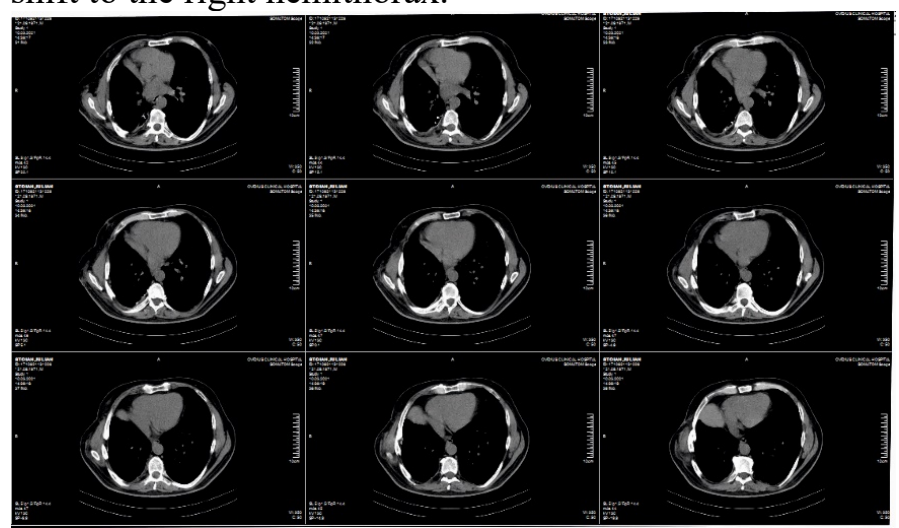

Figure 1 Chest computed tomography

\section{The rehabilitation program}

During hospitalization in the balneal rehabilitation department, several therapeutic procedures were recommended.

Hydro-kinesitherapy in the therapeutic pool with hypertonic saline mineral water at $36^{\circ} \mathrm{C}$ for 20 minutes to assist gait and joint mobility.

Bilateral electrostimulation of the legs to assist and recover the lost movement of the lower legs.

Nano-pulsed electromagnetic field and deep bilateral posterior thoracic oscillation, to stimulate the diaphragm muscle.

Galvanic bath, bilateral knee ultrasound, cervical-dorsal lumbar drainage, lower limb lymphatic drainage and trophic massage in order to improve lower limbs 
circulation and regain muscle trophicity and improve mobility.

Also, the patient benefited from a generalized toning kinesitherapy, kinetic respiratory exercises and treadmill exercises.

\section{Clinical and functional results}

After nearly three weeks of rehabilitation, the patient has improved the general condition

At discharge he did not have muscle or joint pain, no fatigue or physical asthenia. The remission of exertional dyspnea was noted.

The motor deficits diminished motor for both legs as follow: left muscular force dorsiflexion $3+$, inversion $4+$, plantar flexion 5, right muscular force: dorsiflexion 4 , inversion 4, plantar flexion 5 .

Muscles trophicity was improved. There was a significant clinical improvement of the 6 MWT without dyspnea or desaturation (Table 2), increased performance of daily activities, with the ability of climbing stairs 3 , running 5 and lifting weights 4 .

TABLE 2. 6 minutes walking Test at discharge from Balneal and Rehabilitation Sanatorium of Techirghiol

\begin{tabular}{|c|c|}
\hline Before walking & After walking for $\mathbf{4 1 0}$ meters \\
\hline $\mathrm{TA}=120 / 80 \mathrm{~mm} \mathrm{Hg}$ & $\mathrm{TA}=145 / 90 \mathrm{~mm} \mathrm{Hg}$ \\
\hline $\mathrm{AV}=85 \mathrm{rpm}$ & $\mathrm{AV}=113 \mathrm{rpm}$ \\
\hline $\mathrm{SpO} 2=97 \%$ & $\mathrm{SpO} 2=96 \%$ \\
\hline WITHOUT dyspnea & WITHOUT dyspnea \\
\hline \multicolumn{2}{|c|}{ TOTAL DISTANCE COVERED $=410$ meters } \\
\hline
\end{tabular}

\section{Discussion}

In our reported case, we emphasized a complex rehabilitation program consisting in procedures for recovering the bilateral motor deficit of the both lower limbs. The patient had diabetic polyneuropathy but also post-COVID-19 physical deficits, including muscle weakness, induced by prolonged immobilization, neurological impairment, and/or nutritional disorders. Also, the direct infection of the nervous and muscular system, neuroinflammation, post-viral autoimmune response, hypercoagulability, metabolic or hypoxic lesions are assumed as main mechanisms for motor deficits after COVID 1911,12.

Considering the dysfunctional aspects of the post-acute COVID-19 syndrome, mentioned in our reported case, i.e. skeletal muscles and peripheral nerve pathology, the efficacy of rehabilitation was obvious. Complex physical procedures electrostimulation of affected muscles, galvanic bath for reeducation of sensitivity, lymphatic drainage in both lower limbs, toning massage, hydrokinesitherapy for toning and joint stabilization are the guarantor of successful recovery of the lower limbs and the contributor for a better insertion into pre-existing socio-professional and family activities ${ }^{13,14}$. Personalized plans of rehabilitation must be designed according to the age, sex, lifestyle, hobbies, occupation and physical condition of the COVID-19 patients because they might have different degrees of dysfunction ${ }^{14-16}$.

Since SARS-CoV-2 may be prevalent for a long period of time and their sequels as well ${ }^{17}$, routine clinical medical practice has to be adjusted for a greater awareness of early rehabilitation benefits. Initiating rehabilitation in the early stage after the COVID-19 disease $^{18}$ is required in order to prevent negative neurological effects and to improve the functional parameters especially respiratory ones and to improve patients 'quality of life ${ }^{19}$. As a result of the procedures consisting in stimulation of diagram muscle and chest drainage, by deep vibrations, the patient gained autonomy, the walking distance improved considerably by more than 120 meters, and the daily activities were return close to normal. We consider early rehabilitation intervention made immediately after the discharge from intensive care, critical for reducing the burden of the post COVID-19 syndrome, especially in this case with previously altered lung function, caused by TB, with lung fibrosis and respiratory muscle atrophy ${ }^{20}$. The sequels from TB and COVID conditions worse lung capacity $^{21}$ and decrease the tolerance for effort. Respiratory rehabilitation plays an important role in the recovery of body integrity from a pulmonary point of view $^{20}$. There are no sufficient data about the complexity and variability of the lung damage caused by coupled COVID-19 infection and pulmonary TB, and there is limited scientific knowledge and/or evidence about respiratory rehabilitation in patients with both $\mathrm{TB}$ and COVID- $19^{22}$. Owing to lung fibrosis and bronchiectasis, as sequelae of previous pulmonary $\mathrm{TB}$, ventilator associated pneumonia or COVID-19 infection itself, it is difficult to establish their etiology, but further programs of RR are needed and are essential to improve breathing, quality of life and for decreasing the emotional distress ${ }^{23}$. In addition, lung function can be increased through alleviating the neuromuscular weakness by early rehabilitation ${ }^{24}$.

Recurrent elevation of D-dimers, at more than 60 days after the onset of the COVID-19 infection, could have been a risk factor for death, caused by a lung infarction ${ }^{25}$. Therefore, the risk of thrombosis should be considered, especially in patients with severe/critical forms and prolonged hospitalization.

Long COVID-19 syndrome is difficult to manage in patients with previous long-term conditions caused by TB disease ${ }^{17}$. Various sequelae of COVID-19 infection need to be promptly identified because of their life-threatening potential ${ }^{26}$. Further studies are needed to investigate the persistent or recurrent hypercoagulable state, as well as to assess the risk of residual TB lung lesions in patients with immunosuppression caused by diabetes and COVID-19. In conclusion, after a critical form of COVID-19, patients can experience a variety of negative consequences requiring multidisciplinary 
approach and complex individualized programs of rehabilitation in order to restore physical function and mobility, improving daily activities and tolerance to the effort

\section{Author contributions}

All the listed authors contributed equally to this paper. CD, AI, EVI, MGI, LES, SCC, DMI, OCA, VG, FV, MNP, RB, LP: conceptualization, study design, methodology preparation, evaluation of the patient, collecting the data about the patient, analyze the data, writing and editing.

All authors read and approved the final version of the article.

\section{Ethics approval and consent to participate}

This study was conducted in accordance with the declaration of Helsinki and with approval from the Ethics Committee of Balneal and Rehabilitation Sanatorium of Techirghiol from Romania, No 132/ 22.02.2021 Written informed consent was obtained from the patient.

\section{Funding}

This study received no external funding.

\section{Conflict of interest}

The authors declare no conflict of interest.

\section{References}

1. Islam KU, Iqbal J. An Update on Molecular Diagnostics for COVID-19. Front Cell Infect Microbiol. 2020 Nov 10;10:560616. doi: 10.3389/fcimb.2020.560616. PMID: 33244462; PMCID: PMC7683783

2. Dixon BE, Wools-Kaloustian K, Fadel WF, Duszynski TJ, Yiannoutsos C, Halverson PK, Menachemi N. Symptoms and symptom clusters associated with SARS-CoV-2 infection in community-based populations: Results from a statewide epidemiological study. medRxiv [Preprint]. 2020 Oct 22:2020.10.11.20210922. doi: 10.1101/2020.10.11.20210922. Update in: PLoS One. 2021 Mar 24;16(3):e0241875. PMID: 33106813; PMCID: PMC7587833.

3. Yang J, Zheng Y, Gou X, Pu K, Chen Z, Guo Q, Ji R, Wang H, Wang Y, Zhou Y. Prevalence of comorbidities and its effects in patients infected with SARS-CoV-2: a systematic review and metaanalysis. Int J Infect Dis. 2020 May;94:91-95. doi: 10.1016/j.ijid.2020.03.017. Epub 2020 Mar 12. PMID: 32173574; PMCID: PMC7194638.

4. Pascarella G, Strumia A, Piliego C, Bruno F, Del Buono R, Costa F, Scarlata S, Agrò FE. COVID-19 diagnosis and management: a comprehensive review. J Intern Med. 2020 Aug;288(2):192-206. doi: 10.1111/joim.13091. Epub 2020 May 13. PMID: 32348588; PMCID: PMC7267177.

5. Menni C, Valdes AM, Freidin MB, Sudre $\mathrm{CH}$, Nguyen LH, Drew DA, Ganesh S, Varsavsky T, Cardoso MJ, El-Sayed Moustafa JS, Visconti A,
Hysi P, Bowyer RCE, Mangino M, Falchi M, Wolf J, Ourselin S, Chan AT, Steves CJ, Spector TD. Realtime tracking of self-reported symptoms to predict potential COVID-19. Nat Med. 2020 Jul;26(7):10371040. doi: 10.1038/s41591-020-0916-2. Epub 2020 May 11. PMID: 32393804; PMCID: PMC7751267.

6. Spruit MA, Holland AE, Singh SJ, Tonia T, Wilson KC, Troosters T. COVID-19: Interim Guidance on Rehabilitation in the Hospital and Post-Hospital Phase from a European Respiratory Society and American Thoracic Society-coordinated International Task Force. Eur Respir J. 2020 Aug 13;56(6):2002197. doi: 10.1183/13993003.021972020. Epub ahead of print. PMID: 32817258; PMCID: PMC7427118.

7. Kiekens C, Boldrini P, Andreoli A, Avesani R, Gamna F, Grandi M, Lombardi F, Lusuardi M, Molteni F, Perboni A, Negrini S. Rehabilitation and respiratory management in the acute and early postacute phase. "Instant paper from the field" on rehabilitation answers to the COVID-19 emergency. Eur J Phys Rehabil Med. 2020 Jun;56(3):323-326. doi: 10.23736/S1973-9087.20.06305-4. Epub 2020 Apr 15. PMID: 32293817.

8. COVID-19 deaths Report of Romanian Committee to the Ministry of Health. https://media.hotnews.ro/media server1/document2021-05-14-24797182-0-raport-decese-covid-19.pdf (2021, accessed May 15 2020).

9. Didilescu C, Popescu G, Cioran N, Cocei H. Mortalitatea prin tuberculoză in România, un marker al gravităţii endemiei [Mortality of tuberculosis in Romania, a marker for severity of the endemic]. Pneumologia. 2012 Jul-Sep;61(3):150-2. Romanian. PMID: 23173375.Felicia A. Trends of HIV/AIDS Phenomenon Dynamics in Romania from 20172027. Iran J Public Health. 2019 Oct;48(10):19031909. PMID: 31850269; PMCID: PMC6908922.

10. Martijn A. Spruit, Anne E. Holland, Sally J. Singh, Thomy Tonia, Kevin C. Wilson, Thierry Troosters COVID-19: Interim Guidance on Rehabilitation in the Hospital and Post-Hospital Phase from a European Respiratory Society and American Thoracic Society-coordinated International Task Force. Eur RespirJ2020;56(6):2002197.

11. Keyhanian K, Umeton RP, Mohit B, Davoudi B, Hajighasemi F, Ghasemia M. SARS-CoV-2 and nervous system: From pathogenesis to clinical manifestation. J Neuroimmunol. 2021; 350: 577436.

12. Guo Q, Xu W, Wang PF, Ji HY, Zhang XL, Wang K, Li J. Facing coronavirus disease 2019: What do we know so far? (Review). Exp Ther Med. 2021 Jun;21(6):658. doi: 10.3892/etm.2021.10090. Epub 2021 Apr 20. PMID: 33968188; PMCID: PMC8097225. 
13. Sun T, Guo L, Tian F, Dai T, Xing X, Zhao J, Li Q. Rehabilitation of patients with COVID-19. Expert Rev Respir Med. 2020 Dec;14(12):1249-1256. doi: 10.1080/17476348.2020.1811687. Epub 2020 Oct 12. PMID: 32799694.

14. Barker-Davies RM, O'Sullivan O, Senaratne KPP, Baker P, Cranley M, Dharm-Datta S, Ellis H, Goodall D, Gough $\mathrm{M}$, Lewis S, Norman J, Papadopoulou T, Roscoe D, Sherwood D, Turner P, Walker T, Mistlin A, Phillip R, Nicol AM, Bennett AN, Bahadur S. The Stanford Hall consensus statement for post-COVID-19 rehabilitation. Br J Sports Med. 2020 Aug;54(16):949-959. doi: 10.1136/bjsports-2020-102596. Epub 2020 May 31. PMID: 32475821; PMCID: PMC7418628.

15. Pincherle A, Jöhr J, Pancini L, Leocani L, Dalla Vecchia L, Ryvlin P, Schiff ND, Diserens K. Intensive Care Admission and Early NeuroRehabilitation. Lessons for COVID-19? Front Neurol. 2020 Aug 25;11:880. doi: 10.3389/fneur.2020.00880. PMID: 32982916 ; PMCID: PMC7477378.

16. Demeco A, Marotta N, Barletta M, Pino I, Marinaro C, Petraroli A, Moggio L, Ammendolia A. Rehabilitation of patients post-COVID-19 infection: a literature review. J Int Med Res. 2020 Aug;48(8):300060520948382. doi: 10.1177/0300060520948382. PMID: 32840156; PMCID: PMC7450453.

17. Lopez-Leon S, Wegman-Ostrosky T, Perelman C, Sepulveda R, Rebolledo PA, Cuapio A, Villapol S. More than 50 Long-term effects of COVID-19: a systematic review and meta-analysis. medRxiv [Preprint]. 2021 Jan 30:2021.01.27.21250617. doi: 10.1101/2021.01.27.21250617. Update in: Sci Rep. 2021 Aug 9;11(1):16144. PMID: 33532785; PMCID: PMC7852236.

18. Curci C, Pisano F, Bonacci E, Camozzi DM, Ceravolo C, Bergonzi R, De Franceschi S, Moro P, Guarnieri R, Ferrillo M, Negrini F, de Sire A. Early rehabilitation in post-acute COVID-19 patients: data from an Italian COVID-19 Rehabilitation Unit and proposal of a treatment protocol. Eur J Phys Rehabil Med. $2020 \quad$ Oct;56(5):633-641. doi: 10.23736/S1973-9087.20.06339-X. Epub 2020 Jul 15. PMID: 32667150.

19. Wade DT. Rehabilitation after COVID-19: an evidence-based approach. Clin Med (Lond). 2020 Jul;20(4):359-365. doi: 10.7861/clinmed.2020-0353. Epub 2020 Jun 9. PMID: 32518105; PMCID: PMC7385804.

20. Siddiq MAB, Rathore FA, Clegg D, Rasker JJ. Pulmonary Rehabilitation in COVID-19 patients: A scoping review of current practice and its application during the pandemic. Turk J Phys Med Rehabil.
2020 Nov 9;66(4):480-494. doi: 10.5606/tftrd.2020.6889. PMID: 33364571; PMCID: PMC7756838.

21. Tadolini M, Codecasa LR, García-García JM, Blanc FX, Borisov S, Alffenaar JW, Andréjak C, Bachez P, Bart PA, Belilovski E, Cardoso-Landivar J, Centis R, D'Ambrosio L, Luiza De Souza-Galvão $M$, Dominguez-Castellano A, Dourmane S, Fréchet Jachym M, Froissart A, Giacomet V, Goletti D, Grard S, Gualano G, Izadifar A, Le Du D, Marín Royo M, Mazza-Stalder J, Motta I, Ong CWM, Palmieri F, Rivière F, Rodrigo T, Silva DR, SánchezMontalvá A, Saporiti M, Scarpellini P, Schlemmer F, Spanevello A, Sumarokova E, Tabernero E, Tambyah PA, Tiberi S, Torre A, Visca D, Zabaleta Murguiondo M, Sotgiu G, Migliori GB. Active tuberculosis, sequelae and COVID-19 co-infection: first cohort of 49 cases. Eur Respir J. $2020 \mathrm{Jul}$ 9;56(1):2001398. doi: 10.1183/13993003.013982020. PMID: 32457198; PMCID: PMC7251245.

22. Crisan-Dabija R, Grigorescu C, Pavel CA, Artene B, Popa IV, Cernomaz A, Burlacu A. Tuberculosis and COVID-19: Lessons from the Past Viral Outbreaks and Possible Future Outcomes. Can Respir J. 2020 Sep 5;2020:1401053. doi: 10.1155/2020/1401053. PMID: 32934758; PMCID: PMC7479474.

23. Visca D, Ong CWM, Tiberi S, Centis R, D'Ambrosio L, Chen B, Mueller J, Mueller P, Duarte R, Dalcolmo M, Sotgiu G, Migliori GB, Goletti D. Tuberculosis and COVID-19 interaction: A review of biological, clinical and public health effects. Pulmonology. 2021 Mar-Apr;27(2):151-165. doi: 10.1016/j.pulmoe.2020.12.012. Epub 2021 Jan 22. PMID: 33547029; PMCID: PMC7825946.

24. Bissett B, Gosselink R, van Haren FMP. Respiratory Muscle Rehabilitation in Patients with Prolonged Mechanical Ventilation: A Targeted Approach. Crit Care. 2020 Mar 24;24(1):103. doi: 10.1186/s13054020-2783-0. PMID: 32204719; PMCID: PMC7092518.

25. Connors JM, Levy JH. COVID-19 and its implications for thrombosis and anticoagulation. Blood. 2020 Jun 4;135(23):2033-2040. doi: 10.1182/blood.2020006000. PMID: 32339221; PMCID: PMC7273827.

26. Logue JK, Franko NM, McCulloch DJ, McDonald D, Magedson A, Wolf CR, Chu HY. Sequelae in Adults at 6 Months After COVID-19 Infection. JAMA Netw Open. 2021 Feb 1;4(2):e210830. doi: 10.1001/jamanetworkopen.2021.0830. Erratum in: JAMA Netw Open. 2021 Mar 1;4(3):e214572. PMID: 33606031; PMCID: PMC7896197. 